\title{
Mechanical Properties and Environmental Evaluation of Ultra-High-Performance Concrete with Aeolian Sand
}

\author{
Hongyan Chu ${ }^{1, * \mathbb{D}}$, Fengjuan Wang ${ }^{2}$, Liguo Wang ${ }^{2}$, Taotao Feng ${ }^{2}$ and Danqian Wang ${ }^{3}$ \\ 1 College of Civil Engineering, Nanjing Forestry University, Nanjing 210037, China \\ 2 Jiangsu Key Laboratory of Construction Materials, School of Materials Science and Engineering, \\ Southeast University, Nanjing 211189, China; fengjuan19921118@sina.com (F.W.); wlg_seu@sina.com (L.W.); \\ taotao_feng@yeah.net (T.F.) \\ 3 Advanced and Innovative Materials (AIM) Group, Department of Civil, Environmental and Geomatic \\ Engineering, University College London, London WC1E 6BT, UK; danqian.wang.16@ucl.ac.uk \\ * Correspondence: chuhongyan@njfu.edu.cn
}

Received: 19 June 2020; Accepted: 13 July 2020; Published: 15 July 2020

\begin{abstract}
Ultra-high-performance concrete (UHPC) has received increasing attention in recent years due to its remarkable ductility, durability, and mechanical properties. However, the manufacture of UHPC can cause serious environmental issues. This work addresses the feasibility of using aeolian sand to produce UHPC, and the mix design, environmental impact, and mechanical characterization of UHPC are investigated. We designed the mix proportions of the UHPC according to the modified Andreasen and Andersen particle packing model. We studied the workability, microstructure, porosity, mechanical performance, and environmental impact of UHPC with three different water/binder ratios. The following findings were noted: (1) the compressive strength, flexural strength, and Young's modulus of the designed UHPC samples were in the ranges of 163.9-207.0 MPa, 18.0-32.2 MPa, and 49.3-58.9 GPa, respectively; (2) the compressive strength, flexural strength, and Young's modulus of the UHPC increased with a decrease in water/binder ratio and an increase in the steel fibre content; (3) the compressive strength-Young's modulus correlation of the UHPC could be described by an exponential formula; (4) the environmental impact of UHPC can be improved by decreasing its water/binder ratio. These findings suggest that it is possible to use aeolian sand to manufacture UHPC, and this study promotes the application of aeolian sand for this purpose.
\end{abstract}

Keywords: ultra-high-performance concrete; microstructure; Young's modulus; mechanical properties; aeolian sand; environmental assessment

\section{Introduction}

Desertification is one of the most serious global environmental degradation problems, and deserts currently cover approximately $1 / 3$ of the Earth's land area. In China, the desertification area is approximately 1.54 million $\mathrm{km}^{2}$, accounting for approximately $16 \%$ of China's land mass. With the development of the Chinese economy, the construction of China's infrastructure has undergone sustained and rapid development, with the result that building sand availability cannot meet the demand. In particular, there is an acute shortage of medium and coarse sand in north-western China. In addition, in many regions of the Earth (particularly in large arid areas), the shortage of building sand is also a growing problem. However, as a type of solid waste, aeolian sand is very abundant in these regions. Therefore, the development and utilization of aeolian sand have a practical significance from the perspective of sustainable development and have far-reaching social significance and practical engineering value for these areas. 
Studies have been conducted on aeolian sand to evaluate its suitability as a building material. Early research was conducted by Khan [1], who analyzed the chemical and geotechnical properties of aeolian sand collected from the Sahara Desert in Libya, and then systematically discussed various aspects related to expressway construction in arid areas. Detailed experimental investigations were performed by Al-Sanad et al. [2] to obtain the geotechnical properties of dune sand collected from four sites in Kuwait. Yuan et al. [3] and Al-Taie et al. [4] examined the engineering properties of aeolian sand and also investigated the possibility for use as a building material. In addition, other researchers have pointed out that the use of aeolian sand as a fine aggregate in common cement mortar (or concrete) is a practical application $[5,6]$.

Recently, Dong et al. [7] conducted an investigation on the damage evolution in lightweight aggregate concrete containing aeolian sand. The findings suggested that the optimal replacement quantity of river sand with aeolian sand in lightweight-aggregate concrete was $20-30 \%$, and the incorporated aeolian sand had double effects on the damage of this kind of concrete. If the incorporated amount of aeolian sand was higher than 30\%, the damage in the concrete was increased. This damage was reduced when the incorporation amount of aeolian sand was less than $30 \%$.

Lopez-Querol et al. [8] investigated the carrying capacity of cement-stabilized aeolian sand under confined and unconfined conditions with the purpose of using this type of sand in the construction of roads or railways. They concluded that the application of aeolian sand in roads or railways was feasible. However, there are few reports at home or abroad concerning the application of aeolian sand in ultra-high-performance concrete (UHPC). In addition, the properties of concrete are sensitive to environmental effects, and thus researchers also investigated other procedures to improve the behavior of the concrete under various environmental conditions [9-11].

Tremendous progress has been made in relation to the performance of concrete, due to the development of concrete technology. UHPC is a new-type of cementitious composite that is noted for its high mechanical strength and superior durability. Jiang et al. [12] studied the feasibility of using recycled sand to replace natural sand to produce ultra-high-performance cement-based composites (UHPCCs). They found that the properties of the recycled sand UHPCCs were essentially the same as the UHPCCs incorporating natural sand when the substitution rate of recycled sand was lower than $50 \%$.

However, the production of UHPC is relatively expensive due to the utilization of substantial amounts of binders, supplementary cementitious materials, and steel fibres. In addition, when $1000 \mathrm{~kg}$ cement clinker is manufactured, approximately $1000 \mathrm{~kg}$ of carbon dioxide (a type of greenhouse gas) is produced. Researchers estimated that the total amount of carbon dioxide produced by cement reaches approximately $5-7 \%$ of the global anthropogenic carbon dioxide emissions. Thus, the sustainability of UHPC has recently attracted extensive attention, and more efforts should be made to find sustainable solutions for UHPC production.

Various methods have been presented to improve the environmental impact of UHPC. These methods include decreasing the cement content, utilizing supplementary cementitious materials, optimizing the mixture of UHPC, incorporating recycled materials in UHPC, and increasing the durability of UHPC. However, the environmental impact of UHPC demands reasonable and viable production methods. Damineli et al. [13] used the binder intensity and carbon dioxide intensity to define the ecological efficiency of concrete. The binder intensity index denotes the binder needed for adding $1 \mathrm{MPa}$ compressive strength of concrete, whereas the carbon dioxide intensity index denotes the greenhouse gas emissions resulting from the production of concrete. Accordingly, the evaluation of the environmental impact of UHPC requires further investigation, as its components are complex.

Typically, the production of UHPC requires many binding materials. Rossi [14] developed a type of ultra-high-performance cementitious composite, in which $1050 \mathrm{~kg}$ of cement per cubic meter of concrete was used. Ei-Dieb [15] designed an ultra-high strength concrete with approximately $900 \mathrm{~kg}$ of cement and $135 \mathrm{~kg}$ of silica fume per cubic meter. Compared to normal concrete, the cement content in UHPC is typically between 900 and $1100 \mathrm{~kg} / \mathrm{m}^{3}$, which is approximately twice the amount used in normal concrete. Although some studies have demonstrated that it is possible to replace the binding 
materials in UHPC using limestone powder, fine quartz sand, or calcined clay [16-18], it remains a challenging task to find a reasonable balance between the binder content and the comprehensive properties of UHPC.

Brouwers and Radix [19] stated that the improved mechanical properties and superior durability of concrete mainly result from the optimum packing of its granular components. However, in most studies, the UHPC mixtures are directly presented with no detailed explanation [20-25]. Clearly, the available research regarding the mix proportion design of UHPC with an optimized particle packing is inadequate, and some raw materials are not well used in UHPC. In recent years, researchers attempted to design earth-moist concrete [26], ultra-high-performance fibre-reinforced concrete [27], and UHPC [28,29] according to the particle packing theory. In addition, Wang et al. [30] developed a type of UHPC incorporating recycled coral-based materials supported by the particle packing theory. As mentioned above, most investigations have only focused on the mix design or relative properties of UHPC and ignored the environmental impact.

In this work, we investigated the mix proportion design, mechanical characterization, and environmental impact of UHPC made with aeolian sand. The mix proportions of UHPC were designed according to the modified Andreasen and Andersen particle packing theory. $40 \mathrm{wt} . \%$ cement was replaced by fly ash and silica fume in the UHPC designed in this study. Two different steel fibre volume fractions were adopted to assess the influence of the steel fibre content on the mechanical performance and environmental impact of UHPC. The workability, microstructure, porosity, mechanical performance (e.g., compressive strength, flexural strength, and Young's modulus), and environmental impact of UHPCs with three different water/binder ratios were comprehensively studied. An effort was also made to assess the environmental impact of the designed UHPC by utilization of the environmental impact indexes. The findings of this research will improve the application of aeolian sand in UHPC.

\section{Materials and Experimental Methods}

\subsection{Raw Materials}

The binder materials used in the study were P.II 52.5 cement, silica fume, and fly ash. Aeolian sand collected from the Taklimakan desert (Xinjiang, China) was utilized as a fine aggregate. The chemical composition of the cement, fly ash, and aeolian sand are presented in Table 1 . The $\mathrm{SiO}_{2}$ content in the silica fume was higher than $99.00 \mathrm{wt} . \%$. The specific surface and specific gravity of cement were $362.20 \mathrm{~m}^{2} / \mathrm{kg}$ and 3.15, respectively, and the specific surface and specific gravity of silica fume were $2.79 \times 10^{4} \mathrm{~m}^{2} / \mathrm{kg}$ and 2.22 , respectively. The particle size distribution of the raw materials is presented in Figure 1.

Table 1. Chemical compositions of the cement, fly ash, and aeolian sand (wt.\%).

\begin{tabular}{cccc}
\hline Materials & Cement & Fly Ash & Aeolian Sand \\
\hline $\mathrm{CaO}$ & 64.70 & 8.38 & 2.07 \\
$\mathrm{SiO}_{2}$ & 20.40 & 47.96 & 81.72 \\
$\mathrm{Al}_{2} \mathrm{O}_{3}$ & 4.70 & 30.46 & 8.19 \\
$\mathrm{Fe}_{2} \mathrm{O}_{3}$ & 3.38 & 5.91 & 1.49 \\
$\mathrm{MgO}$ & 0.87 & 2.60 & 0.84 \\
$\mathrm{SO}$ & 1.88 & 1.32 & 0.08 \\
$\mathrm{~K}_{2} \mathrm{O}$ & 0.83 & 1.61 & 2.12 \\
$\mathrm{Na}_{2} \mathrm{O}$ & - & 1.76 & 1.67 \\
$\mathrm{Loss}$ & 3.24 & - & 1.82 \\
\hline
\end{tabular}




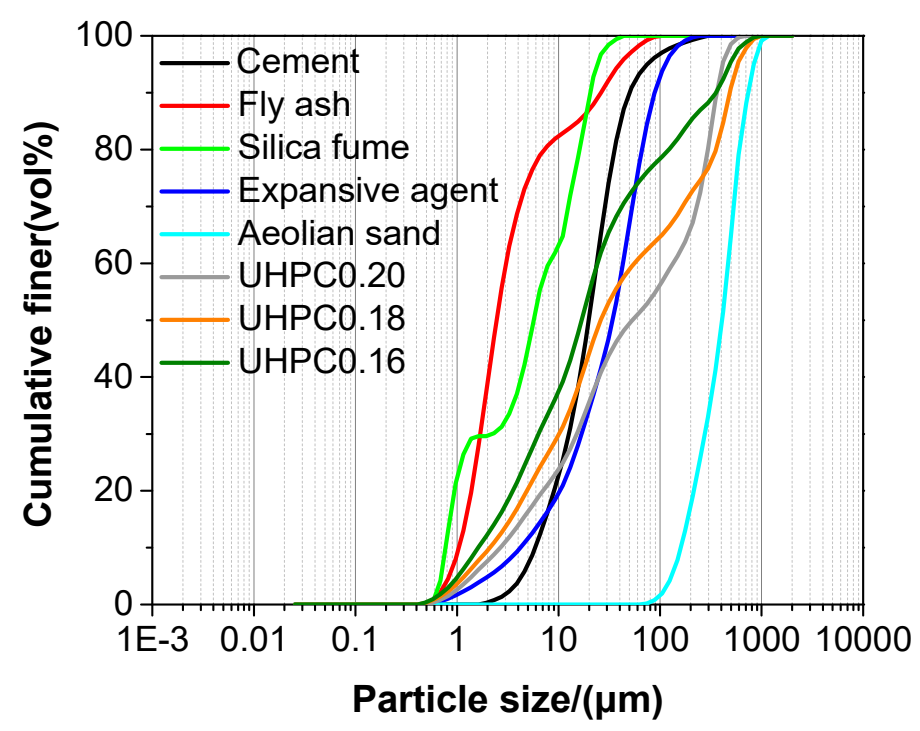

Figure 1. The particle size distribution of the raw materials.

We utilised a superplasticiser of polycarboxylate to obtain a satisfactory workability of the UHPC, and the water-reducing rate of the superplasticiser was 33.9\%. The size of the steel fibres incorporated in the work was $0.2 \mathrm{~mm}$ (diameter) $\times 13 \mathrm{~mm}$ (length), and the tensile strength was approximately 3.0 GPa. A CaO expansive agent was utilised in the study, and its content was $5 \mathrm{wt} . \%$ of cement.

\subsection{Mix Proportion Design of UHPC}

In the mix proportion design procedure, the UHPC mixtures were adequately designed according to the particle packing theory. The modified Andreasen \& Andersen particle packing theory [31] was applied in this work, which is expressed as follows:

$$
V(S)=\left(S^{d}-S_{\min }^{d}\right) /\left(S_{\max }^{d}-S_{\min }^{d}\right)
$$

where $S$ is the particle size, and $V(S)$ is the cumulative volume fraction smaller than size $S . d, S_{\text {min }}$, and $S_{\max }$ are the distribution modulus, minimum particle size, and maximum particle size, respectively.

In this study, $d$ was set at 0.23 based on previous research findings [27,29]. For how to design the UHPC using particle packing theory, the details are available in published papers $[27,28,32]$. For simplicity, the theoretical grading curves that were calculated from Equation (1) of UHPC with different water/binder ratios are also plotted in Figure 1. According to the findings of Wille and Boisvert-Cotulio [33], the aggregate/cement ratio of the UHPC mixtures was 1.33 (see Table 2).

Table 2. Mixtures of ultra-high-performance concrete (UHPC) $\left(\mathrm{kg} / \mathrm{m}^{3}\right)$.

\begin{tabular}{ccccccc}
\hline Mixture & U0.20F2.5 & U0.20F3.0 & U0.18F2.5 & U0.18F3.0 & U0.16F2.5 & U0.16F3.0 \\
\hline Cement & 646.2 & 646.2 & 660.6 & 660.6 & 675.6 & 675.6 \\
Fly ash & 323.1 & 323.1 & 330.3 & 330.3 & 337.8 & 337.8 \\
Silica fume & 107.7 & 107.7 & 110.1 & 110.1 & 112.6 & 112.6 \\
Aeolian sand & 861.8 & 861.8 & 880.8 & 880.8 & 900.6 & 900.6 \\
Water & 215.4 & 215.4 & 198.2 & 198.2 & 180.2 & 180.2 \\
Superplasticizer & 21.5 & 21.5 & 22.0 & 22.0 & 22.5 & 22.5 \\
$\begin{array}{c}\text { Expensive agent } \\
\text { Steel fibre }\end{array}$ & 32.3 & 32.3 & 33.0 & 33.0 & 33.8 & 33.8 \\
$\begin{array}{c}\text { Aggregate/cement ratio } \\
\text { (in weight) }\end{array}$ & 195.0 & 234.0 & 195.0 & 234.0 & 195.0 & 234.0 \\
\hline
\end{tabular}


The mixing proportions of the UHPC were designed in accordance with the optimised particle packing theory, and they are listed in Table 2. In total, three different types of UHPC were designed, and their water/binder ratios were $0.20,0.18$, and 0.16 , respectively. For UHPC, the steel fibre content is typically $2-5 \mathrm{vol} \%$ [34]. Thus, two different steel fibre contents ( $2.5 \mathrm{vol} \%$ and $3.0 \mathrm{vol} \%$ ) were used for each water/binder ratio in the study.

\subsection{Specimen Preparation}

To obtain a homogenous mixture, the P.II 52.5 cement, fly ash, and silica fume were mixed using a mixer for $5 \mathrm{~min}$, then these binders were mixed with fine aggregate for $5 \mathrm{~min}$. Subsequently, the dry materials were mixed with water and the superplasticiser for $10 \mathrm{~min}$, and the steel fibre was added during the $5 \mathrm{~min}$ of final mixing. The superplasticiser was mixed evenly with a part of the water, and this mixed solution was then poured into the dry materials.

After mixing, cubic (size: $70.7 \mathrm{~mm} \times 70.7 \mathrm{~mm} \times 70.7 \mathrm{~mm}$ ) and prismatic (sizes: $70 \mathrm{~mm} \times 70 \mathrm{~mm} \times 280 \mathrm{~mm}$ and $70.7 \mathrm{~mm} \times 70.7 \mathrm{~mm} \times 220 \mathrm{~mm}$ ) specimens of UHPC were cast. First, the surfaces of the samples were covered with plastic sheeting after casting. Secondly, the samples were cured for approximately $48 \mathrm{~h}$ under room temperature conditions before demoulding. Thirdly, the samples were cured for 28 days under the condition that the temperature was $21 \pm 1^{\circ} \mathrm{C}$ and the relative humidity was above $95 \%$. Five cubic, six prismatic (size: $70 \mathrm{~mm} \times 70 \mathrm{~mm} \times 280 \mathrm{~mm}$ ), and ten prismatic (size: $70.7 \mathrm{~mm} \times 70.7 \mathrm{~mm} \times 220 \mathrm{~mm}$ ) specimens were made for each mixture of UHPC. All the specimens of UHPC were prepared according to the Chinese standard GB 50204-2015 [35].

\subsection{Testing Methodology}

The slump flow of the UHPC samples was measured with a normal concrete slump cone set based on the Chinese standard GB 50119-2013 [36]. (similar to ASTM C143). In this study, the microstructure of the UHPC was characterized using 3D environmental scanning electronic microscopy (ESEM). The specimens were crushed into small fragments and immersed in alcohol to prevent their further hydration when the curing treatment was finished. The specimens were then dried and stored in a sealed jar before testing. The porosity and pore size distributions of the UHPC were tested via the mercury intrusion porosimeter (AutoPore IV; Micromeritics, Norcross, GA, USA). The compressive strength of the UHPC was measured via a universal testing machine with a loading rate of $0.80 \mathrm{MPa} / \mathrm{s}$. A four-point bending loading configuration was utilised to test the flexural strength of the UHPC, and the space between the loading points was $210 \mathrm{~mm}$, in which region there was no shear force. The Young's modulus of the UHPC was measured using a universal testing machine equipped with a micro-deformation testing facility, and the loading rate of the experiment was also $0.8 \mathrm{MPa} / \mathrm{s}$.

All the mechanical properties of the UHPC were measured after the curing treatment based on the Chinese standard GB/T 17617-1999 [37]. (which is similar to ASTM C109). The UHPC specimen size for compressive strength was $70.7 \mathrm{~mm} \times 70.7 \mathrm{~mm} \times 70.7 \mathrm{~mm}$, and the specimen sizes for the four-point bending flexural strength test and Young's modulus test were $70 \mathrm{~mm} \times 70 \mathrm{~mm} \times 280 \mathrm{~mm}$ and $70.7 \mathrm{~mm} \times 70.7 \mathrm{~mm} \times 220 \mathrm{~mm}$, respectively. The porosity, compressive strength, and flexural strength of the UHPC were measured three repeated times, and the Young's modulus of the UHPC was tested six repeated times.

\subsection{Environmental Assessment}

In this work, the embedded carbon dioxide index (ECI) and the unit cement compressive strength contribution index (UCI) were used to characterize the environmental impact of the UHPC. The definitions of these two indexes are as follows:

$$
\begin{gathered}
\mathrm{ECI}=\text { embodied carbon dioxide }\left(\mathrm{kg} / \mathrm{m}^{3}\right) / \text { compressive stress }(\mathrm{MPa}) \\
\mathrm{UCI}=\text { compressive stress }(\mathrm{MPa}) / \text { cement content }\left(\mathrm{kg} / \mathrm{m}^{3}\right)
\end{gathered}
$$


According to the findings of Long et al. [38], the embedded carbon dioxide of UHPC was calculated during the phases of processing raw materials and the curing of concrete. Hence, the carbon dioxide emissions of UHPC is the sum of the embedded carbon dioxide in its raw materials and curing process. The embedded carbon dioxide of the raw materials used in UHPC production has been studied by many researchers and, according to these previous studies, the embedded carbon dioxide of each type of raw material is presented in Table 3. The embedded carbon dioxide of the aeolian sand is the same as that of the river sand, and the embedded carbon dioxide of the expansive agent is the average embedded carbon dioxide of the air entraining and retarder agents shown in the paper of Long et al. [38]. To ensure the required strength, the specimens of UHPC were cured in a standard curing room for 28 days. The total carbon dioxide emissions were calculated from the power consumption of the curing room, namely, $1.19 \mathrm{kw} \times 24 \mathrm{~h} \times 28$ days $\times 0.997 \mathrm{~kg} /(\mathrm{kw} \cdot \mathrm{h})=797.2810 \mathrm{~kg} / \mathrm{m}^{3}$; thus, the average embedded carbon dioxide for each type of UHPC in this study was $132.8802 \mathrm{~kg} / \mathrm{m}^{3}$.

Table 3. Embedded $\mathrm{CO}_{2}$ of the raw materials of ultra-high-performance concrete (UHPC).

\begin{tabular}{cccc}
\hline Items & Unit & Embedded $\mathbf{C O}_{\mathbf{2}} \mathbf{( k g )}$ & Reference \\
\hline Cement & $\mathrm{kg}$ & 0.8324 & {$[39]$} \\
Fly ash & $\mathrm{kg}$ & 0.0090 & {$[38]$} \\
Silica fume & $\mathrm{kg}$ & 0 & {$[39]$} \\
Aeolian sand & $\mathrm{kg}$ & 0.0010 & \\
Water & $\mathrm{kg}$ & 0.0003 & {$[38]$} \\
Superplasticizer & $\mathrm{kg}$ & 0.7200 & {$[38]$} \\
Expensive agent & $\mathrm{kg}$ & 0.0810 & \\
Steel fibre & $\mathrm{kg}$ & 1.4965 & {$[39]$} \\
\hline
\end{tabular}

\section{Results and Discussion}

\subsection{Workability of UHPC}

The slump test results of the UHPCs are presented in Table 4. As shown in Table 4, the slump flow of UHPC decreased with decreasing water/binder ratio, which is in line with the results of UHPC made of river sand reported in the literature [40]. The minimum slump flow of UHPC was $570 \mathrm{~mm}$, which still meets the requirements of self-consolidating concrete. When the steel fibre content was $2.5 \mathrm{vol} \%$, the slump flows of UHPC with water/binder ratios of 0.18 and 0.16 decreased by $13.9 \%$ and $30.0 \%$, respectively, compared to the UHPC whose water/binder ratio was 0.20 .

Table 4. Slump flow of the UHPC samples (mm).

\begin{tabular}{ccccccc}
\hline Mixture & U0.20F2.5 & U0.20F3.0 & U0.18F2.5 & U0.18F3.0 & U0.16F2.5 & U0.16F3.0 \\
\hline Slump flow & 900 & 840 & 775 & 700 & 630 & 570 \\
\hline
\end{tabular}

When the water/binder ratio remained constant, the slump of UHPC decreased with the rise in steel fibre content, which is consistent with the findings of Alsalman et al. [35], who also found that the workability of UHPC made of river sand was decreased due to the increase of steel fibre. When the steel fibre content increased from $2.5 \mathrm{vol} \%$ to $3.0 \mathrm{vol} \%$, the slump flows of UHPCs with water/binder ratios of $0.20,0.18$, and 0.16 , decreased by $6.67 \%, 9.68 \%$, and $9.52 \%$, respectively. On the one hand, the specific surface area was enlarged due to the increment in steel fibre, and thus, the cohesive force between the steel fibre and cement paste was higher [41]. On the other hand, the inter-connection of steel fibres in the cement paste generated a skeleton, which could further inhibit the fluidity of the UHPC [28,42].

\subsection{Microstructure}

The ESEM images of the UHPC samples are presented in Figure 2. 


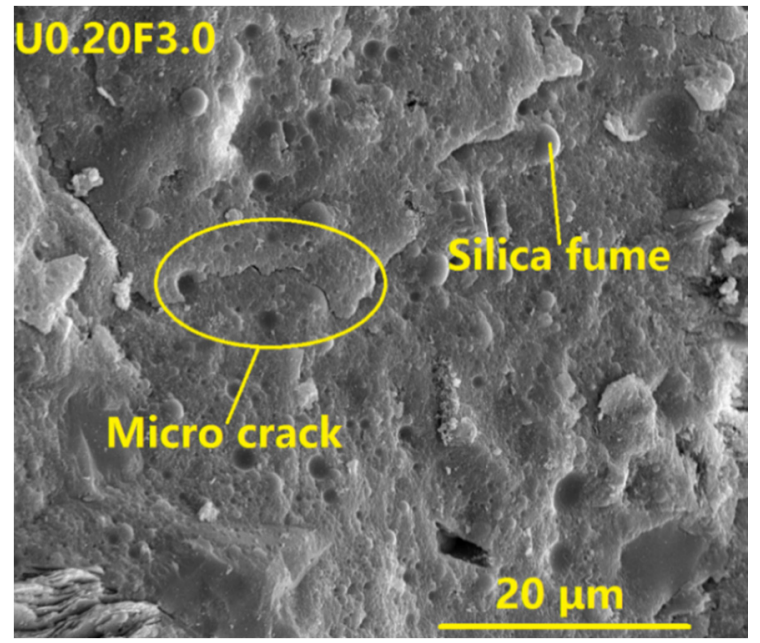

(a)

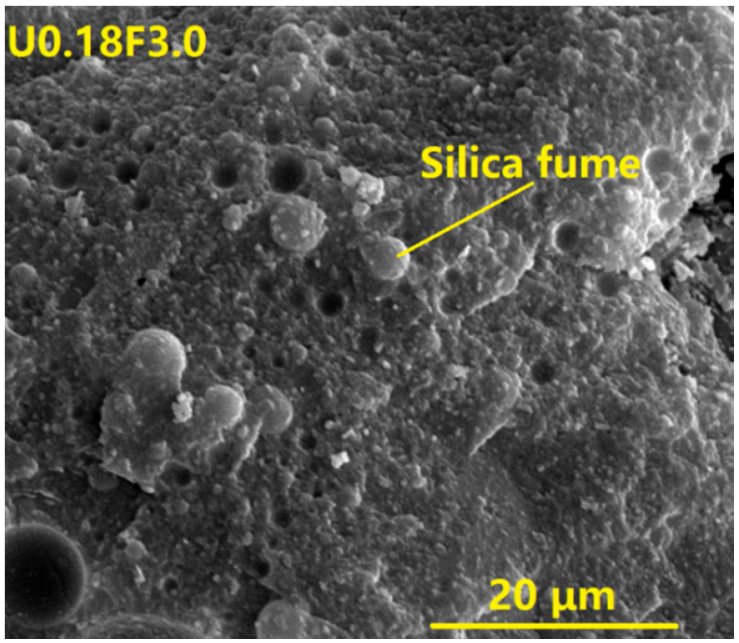

(b)

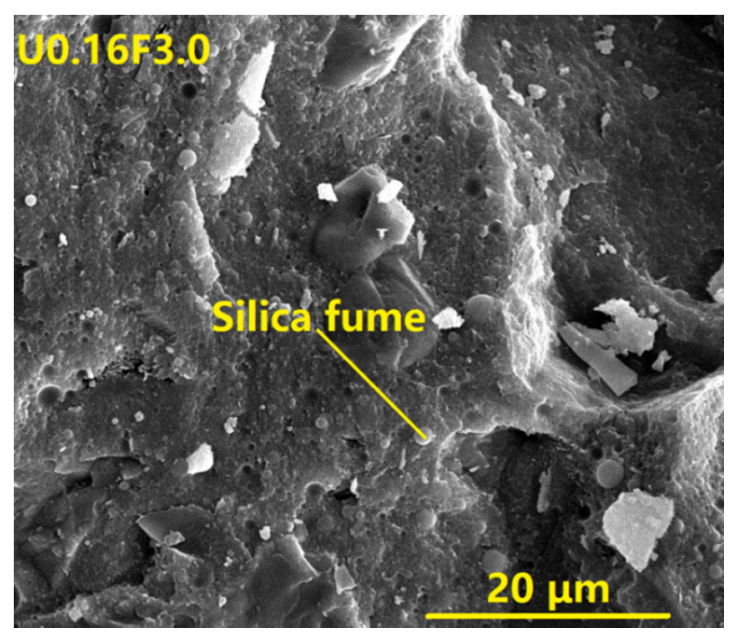

(c)

Figure 2. Micrographs of the different kinds of UHPC at 28 days.

The matrices of U0.18F3.0 and U0.16F3.0 exhibited a continuous microstructure without micro cracks (see Figure 2), and this result was consistent with sacrificial concrete at ambient temperature [43] and UHPC [24]. The matrix of U0.20F3.0 displayed a continuous microstructure with some micro cracks, which was in line with the findings of Meng and Khayat [44]. There was a large quantity of spherical silica fume particles in the matrices of UHPC due to the addition of silica fume, as is vividly depicted in the micrographs of U0.20F3.0, U0.18F3.0, and U0.16F3.0. In addition, the matrices of U0.18F3.0 and U0.16F3.0 were more compact than that of U0.20F3.0, which indicated that the microstructure of UHPC could be improved if the water/binder ratio decreased.

\subsection{Porosity}

Figure 3 presents the porosity and pore size distribution of different types of UHPC. After the curing treatment, the porosities of U0.20F3.0, U0.18F3.0, and U0.16F3.0 were 3.07\%, 2.53\%, and 1.92\%, respectively, which followed the sequence U0.20F3.0 > U0.18F3.0 > U0.16F3.0, as shown in Figure 3a. The porosity of UHPC was lower than that of high-strength concrete [45], and this was similar to the findings of Yu et al. [27], Wang et al. [46], and Jiang et al. [47]. The porosities of U0.18F3.0 and U0.16F3.0 were invariably lower than that of U0.20F3.0, which suggested that the porosity of UHPC diminished when the water/binder ratio of UHPC was reduced. The air content of UHPC increased 
with the decreasing water/binder ratio; thus, the porosity might increase again when the newly generated hydration products were not sufficient to fill the pores resulting from the air entrained in the fresh UHPC.

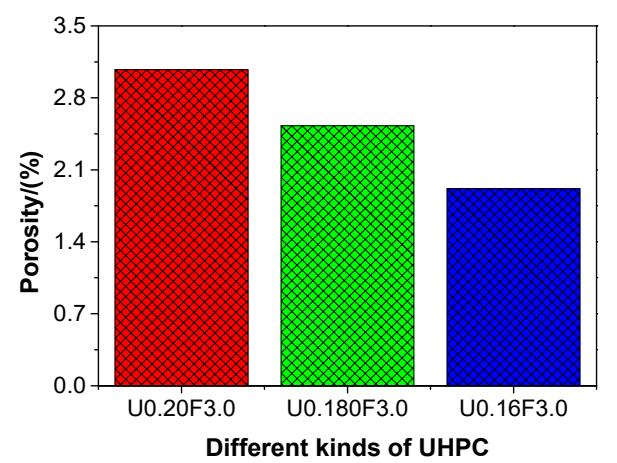

(a)

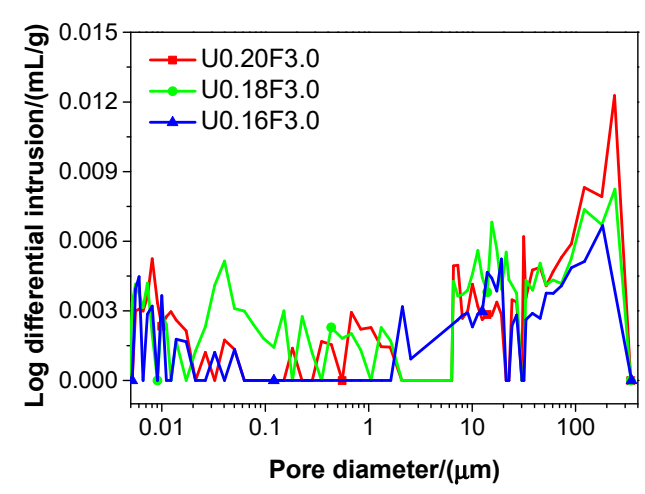

(b)

Figure 3. The porosity (a) and pore size distribution (b) of different kinds of UHPC at 28 days.

With respect to the pore size distribution of U0.20F3.0, U0.18F3.0, and U0.16F3.0, there were multi peaks in the different types of UHPC, as presented in Figure $3 \mathrm{~b}$. The changing trend of the pore diameter in UHPC was in agreement with that in sacrificial concrete at $25^{\circ} \mathrm{C}$ [48]. In addition, the changing trends of pore diameter in different kinds of UHPC were fairly close to each other. In general, the magnitude of the Log differential intrusion for different types of UHPC followed the sequence $\mathrm{U} 0.20 \mathrm{~F} 3.0>\mathrm{U} 0.18 \mathrm{~F} 3.0>\mathrm{U} 0.16 \mathrm{~F} 3.0$, which was in accordance with the porosity results of the UHPC.

\subsection{Compressive Strength}

Figure 4 presents the compressive strength of different types of UHPC with aeolian sand. As the water/binder ratio declined, the compressive strength of UHPC gradually increased (except for $\mathrm{U} 0.16 \mathrm{~F} 2.5$ ), as shown in the figure. These results were different (in part) from those presented by $\mathrm{Yu}$ et al. [49]. The compressive strength of UHPC produced in this work was in the range of 163.9-207.0 MPa, which is clearly higher than the requirement for the mechanical strength of UHPC (i.e., compressive strength $>150 \mathrm{MPa}$ ) [50]. In general, the compressive strength of UHPC increased as the porosity reduced (Figure 3a), and this result was in line with the findings of Siddique [51].

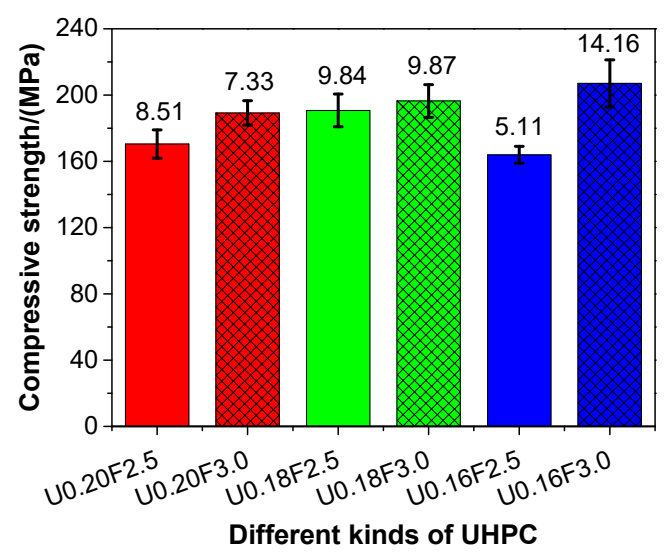

Figure 4. The compressive strength of different kinds of UHPC at 28 days.

Regarding the impact of the steel fibre content on the compressive strength of UHPC, this was clearly increased when the steel fibre content increased from 2.5 to $3.0 \mathrm{vol} \%$, which suggested that the adoption of steel fibre was conducive to the improvement in the compressive strength of UHPC. This 
result is line with the finding of Su et al. [52], who also found that the compressive strength of UHPC made of natural sand was increased due the increase of steel fibre. When the water/binder ratios of UHPC with aeolian sand were $0.20,0.18$, and 0.16 , the compressive strength of UHPC increased by $11.03 \%, 2.99 \%$, and $26.30 \%$, respectively, with the increasing steel fibre content. In most instances, the compressive strength of the concrete declined gradually as the water content was increased, as the excessive water could increase the porosity of concrete. However, a large amount of cement and supplementary cementitious materials, and limited water, were used in the UHPC. A large amount of water was absorbed by the powders and could not react with the cement when the water/binder ratio was small, which, in turn, reduced the compressive strength of the UHPC. This was possibly the reason why the compressive strength of U0.16F2.5 was the lowest.

\subsection{Flexural Strength}

Figure 5 presents the flexural strength of UHPCs with different water/binder ratios. As shown in Figure 5, the flexural strength of UHPC slowly increased, except for U0.16F2.5, with the decrease in the water/binder ratio. The flexural strength of the UHPC ranged from 18.0 to $32.2 \mathrm{MPa}$. The changing trends of flexural strength of the UHPC were in line with those of the compressive strength of UHPC. In addition, with the decrease in porosity (Figure 3a), the flexural strength of UHPC increased in this study, and this result was in line with the findings reported in the literature [50]. The flexural strength of the UHPC increased when the steel fibre content grew from 2.5 to $3.0 \mathrm{vol} \%$, which indicated that the flexural strength of the UHPC could be improved by adopting steel fibres.

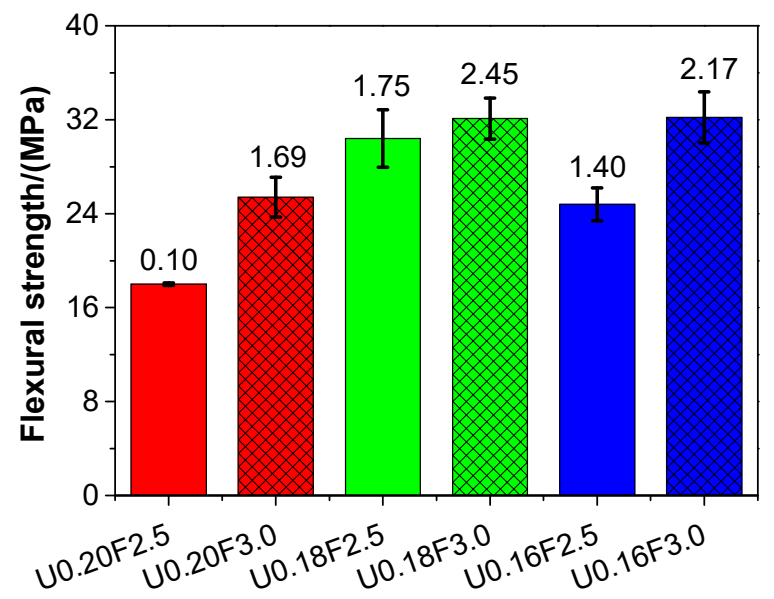

Different kinds of UHPC

Figure 5. The flexural strength of different kinds of UHPC at 28 days.

This result is consistent with the previous literature [52], which suggested that the flexural strength of UHPC produced by natural sand increased with the increase of steel fibre. Specifically, when the water/binder ratios of UHPC were $0.20,0.18$, and 0.16 , the flexural strength of the UHPC increased by $41.11 \%, 5.59 \%$, and $29.84 \%$, respectively, due to the increasing steel fibre content. The increase in magnitude of the flexural strength was higher than that of the compressive strength of UHPC. Thus, the flexural strength of UHPC could be more easily improved than its compressive strength with the addition of steel fibres.

The load-deflection curves of different types of UHPC are illustrated in Figure 6. The load of UHPC increased linearly with the increase of mid-span deflection before reaching the maximum, and then degraded in a plastic manner due to the incorporation of steel fibres. 


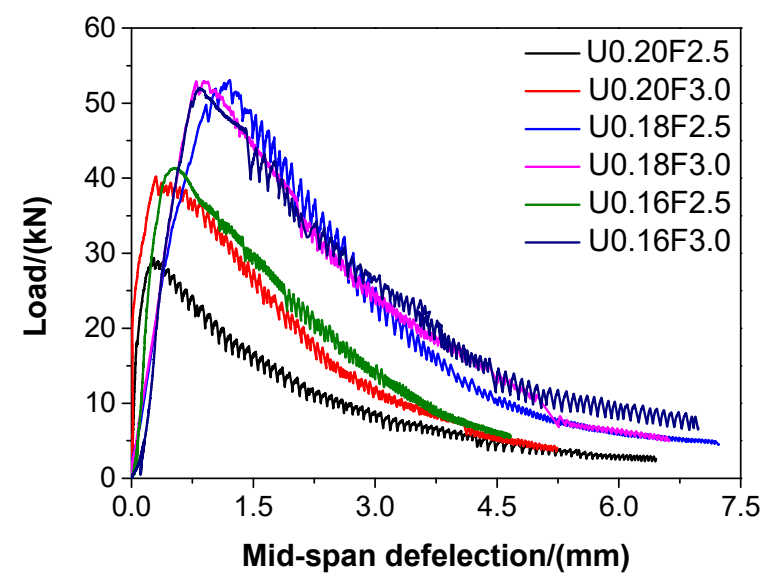

Figure 6. Load-deflection relationships of the UHPCs.

According to Bazant [53], the fracture energy of concrete materials denotes the needed energy for crack propagation in these kinds of materials. The fracture energy is obtained via Equations as follows:

$$
\begin{gathered}
P_{0}=4 M_{0} / l \\
W_{F}=W_{0}+2 P_{0} d_{0}
\end{gathered}
$$

where $d_{0}$ is the maximum mid-span displacement, $l$ is the distance between two supports, $M_{0}$ is the moment caused by the self-weight of the specimen, and $W_{0}$ is the work done by a load that is applied, namely, the area enclosed by the load-deflection curve.

Hence, the fracture energy of UHPC was calculated by the following equation:

$$
G_{F}=W_{F} / S
$$

where $G_{F}$ is the fracture energy and $S$ is the cross-sectional area.

According to Equations (4)-(6), the fracture energies of UHPC could be determined, and they are listed in Table 5. With the decreasing of water/binder ratio, the fracture energy of UHPC gradually increased, except for U0.16F2.5, which suggested that the plasticity of UHPC could be improved if the water/binder ratio of UHPC was decreased. The changing trend of the fracture energy of UHPC was consistent with that of the flexural strength (Figure 5). The fracture energy of UHPC increased when the added steel fibre increased from 2.5 to $3.0 \mathrm{vol} \%$, which indicated that the plasticity of UHPC could be enhanced by adding steel fibres. This result is accordant with Su et al. [52], who suggested that the fracture energy of UHPC produced by natural sand was increased due the increase of steel fibres. In particular, when the water/binder ratios of UHPC were $0.20,0.18$, and 0.16 , the fracture energy of UHPC increased by $49.42 \%, 0.90 \%$, and $43.68 \%$, respectively, owing to the increasing steel fibre content. It can be seen from Figure 6 that the load-deflection curves of U0.18F2.5 and U0.18F3.0 were very close, which indicated that the difference for the fracture energy of these two mixtures was narrow. However, the load-deflection curves of U0.16F2.5 and U0.18F2.5, and U0.16F2.5 and U0.18F3.0, respectively, had dramatic differences, which suggested the difference for the fracture energy of these mixtures were significant. These might be the reasons why the increasing magnitude of fracture energy for different UHPCs was significant.

Table 5. The fracture energy of the UHPC samples $\left(\mathrm{J} / \mathrm{m}^{2}\right)$.

\begin{tabular}{ccccccc}
\hline Mixture & U0.20F2.5 & U0.20F3.0 & U0.18F2.5 & U0.18F3.0 & U0.16F2.5 & U0.16F3.0 \\
\hline Fracture energy & 60.3 & 90.1 & 132.6 & 133.8 & 94.1 & 135.2 \\
\hline
\end{tabular}




\subsection{Young's Modulus}

The Young's modulus values of the UHPCs are presented in Figure 7.

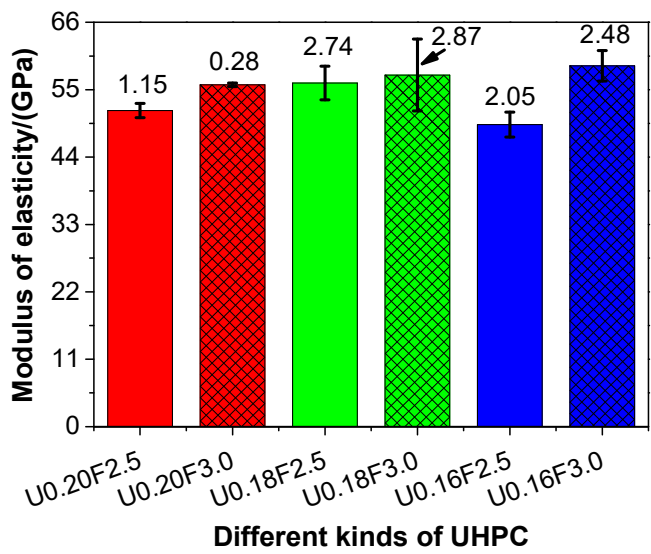

Figure 7. The Young's modulus of different kinds of UHPC at 28 days.

As shown in Figure 7, the Young's modulus of the UHPC increased as the water/binder ratio reduced, except for U0.16F2.5. These results suggested that the Young's modulus of UHPC could be improved with a decrease in the water/binder ratio. The Young's modulus of the UHPC was in the range of 49.3-58.9 GPa, and these values were higher than those reported in the literature [41]. The stiffness of the UHPC mainly resulted from the sand skeleton [54], as the skeleton generated by the sand particles had a higher stiffness than that of the hardened cement matrix. The Young's modulus of the UHPC increased when the steel fibre content increased from 2.5 to $3.0 \mathrm{vol} \%$, which indicated that the adoption of steel fibre contributed to enhancing the Young's modulus of the UHPC. Specifically, the Young's modulus of the UHPC increased by $8.14 \%, 2.32 \%$, and $19.47 \%$ owing to the increasing steel fibre content when the water/binder ratios were $0.20,0.18$, and 0.16 , respectively. These results were in line with the experimental results of Alsalman et al. [41]. In addition, the changing trend of the Young's modulus of the UHPC was consistent with that of the compressive strength, which revealed that the Young's modulus of the UHPC might be characterised by its compressive strength. As mentioned above, the mechanical properties (compressive strength, flexural strength, and Young's modulus) of UHPC increased when the steel fibre content increased; thus, the recommended value of steel fibre was $3.0 \mathrm{vol} \%$ in terms of mechanical properties of UHPC.

\subsection{Compressive Strength-Young's Modulus Correlation}

Figure 8 shows the compressive strength-Young's modulus correlation of the UHPC.

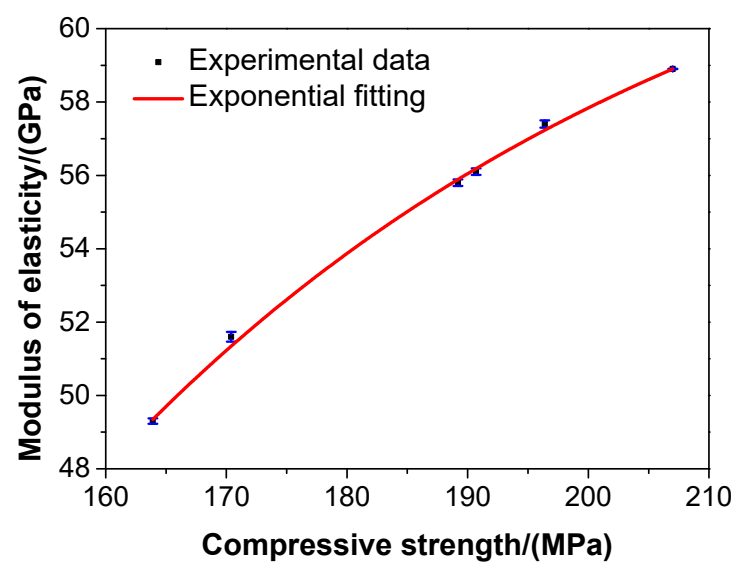

Figure 8. The relationship between the compressive strength and Young's modulus of the UHPC. 
As presented in Figure 8, the Young's modulus of the UHPC increased gradually with the increase of compressive strength. The compressive strength of the UHPC had a strong correlation with the Young's modulus, and the compressive strength-Young's modulus correlation of the UHPC was in an exponential form, shown as the full curve in Figure 8. This exponential form is expressed by the following formula:

$$
\mathrm{E}=65.88472-429.48946 \times e^{-0.01989 f_{c}}
$$

where $\mathrm{E}$ is the Young's modulus of the UHPC in GPa, and $f_{c}$ is the compressive strength of the UHPC in MPa.

The $R$-square of the above equation was 0.9975 , which suggested that the results of data fitting were rather reliable, and that Equation (5) was feasible to evaluate the Young's modulus of the UHPC in terms of the compressive strength. The empirical formula obtained in the study may not precisely capture the behavior of UHPC with different aggregate types or particle sizes. However, a new empirical equation was developed in the study. In practice, this was a convenient method to assess the Young's modulus of the UHPC in terms of its compressive strength via the abovementioned equation.

\subsection{Environmental Assessment}

The results of ECI and UCI for different types of UHPC are presented in Figure 9. The ECI of UHPC declined with the reduction in water/binder ratio, except for U0.16F2.5, under the same steel fibre content (see Figure 9a), which suggested that the environmental impact of UHPC could be improved with a decrease in the water/binder ratio. When the water/binder ratio decreased, the binder content of UHPC increased, which resulted in the increase of $\mathrm{CO}_{2}$ emissions and the compressive strength of UHPC. However, the increase in magnitude of the $\mathrm{CO}_{2}$ emissions was lower than that of compressive strength. Therefore, the ECI of UHPC was reduced with the decrease of water/binder ratio, according to Equation (2).

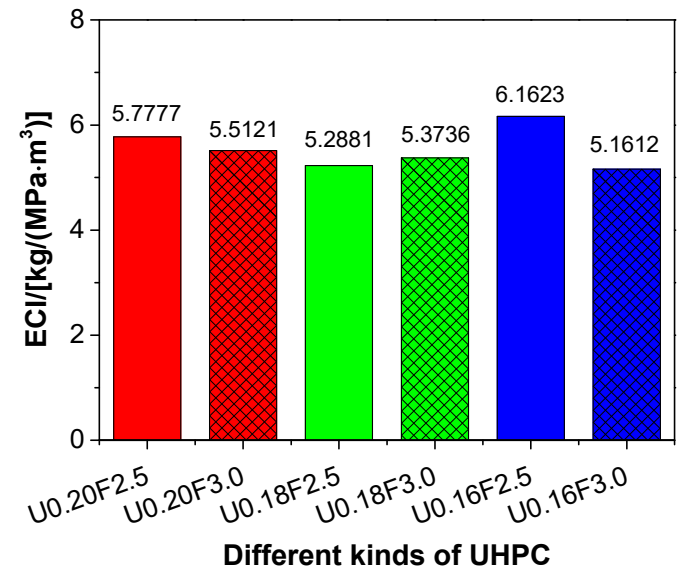

(a)

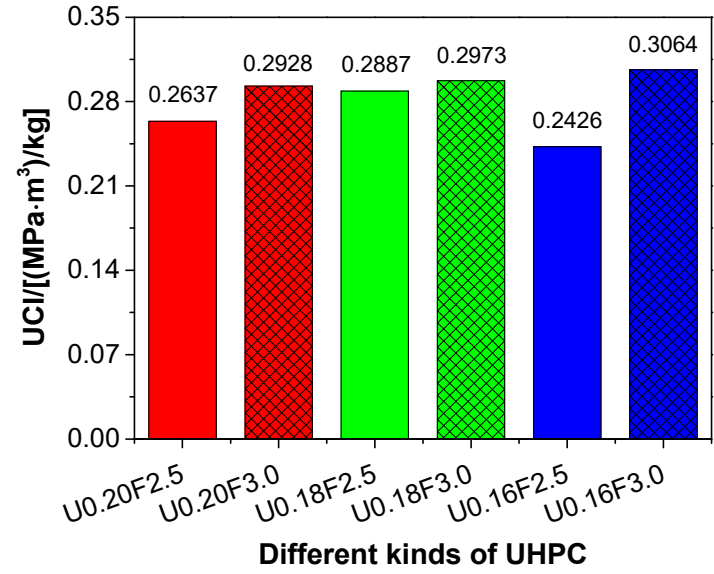

(b)

Figure 9. The environmental assessment of UHPC: (a) ECI and (b) UCI.

The results of ECI and UCI for different types of UHPC are presented in Figure 9. The ECI of UHPC declined with the reduction in water/binder ratio, except for U0.16F2.5, under the same steel fibre content (see Figure 9a), which suggested that the environmental impact of UHPC could be improved with a decrease in the water/binder ratio. When the water/binder ratio decreased, the binder content of UHPC increased, which resulted in the increase of $\mathrm{CO}_{2}$ emissions and the compressive strength of UHPC. However, the increase in magnitude of the $\mathrm{CO}_{2}$ emissions was lower than that of compressive strength. Therefore, the ECI of UHPC was reduced with the decrease of water/binder ratio, according to Equation (2). 
Contrary to the ECI, the UCI of UHPC increased with the decrease in water/binder ratio (except for U0.16F2.5) under the same steel fibre content (see Figure 9b), which indicated that the environmental impact of UHPC could also be enhanced owing to a decrease in the water/binder ratio. The water/binder ratio of the UHPC declined when the binder content of the UHPC increased, which in turn caused an increase in the compressive strength. The increase in magnitude of the compressive strength was higher than that of the binder content of the UHPC. Hence, the UCI of the UHPC was increased with the decrease in water/binder ratio, according to Equation (3). Overall, the environmental impact of UHPC could be improved by decreasing its water/binder ratio. In addition, the UCI of UHPC increased with the increase of steel fibre content under the same water/binder ratio (see Figure 9b), which suggested that the environmental impact of UHPC could also be enhanced by adding more steel fibres. Therefore, the recommended value of steel fibre was $3.0 \mathrm{vol} \%$ in terms of the environmental impact of UHPC. Compared to all other mixtures, the ECI of U0.16F3.0 was the lowest and its UCI was the largest, which suggested that the mix design of U0.16F3.0 had the lowest environmental impact.

The compressive strength-ECI correlation of UHPC is shown in Figure 10, where it can be observed that the ECI gradually decreased with the increase in compressive strength in any conditions of the steel fibre content and water/binder ratio of the UHPC in this work. These results are consistent with those found by Shi et al. [55] and Long et al. [38] and in line with the similar results obtained for UHPC and self-compacting concrete. The compressive strength-ECI correlation of UHPC is expressed by the following exponential function:

$$
\mathrm{ECI}=11.55178 \times e^{-0.00396 f_{c}}
$$

where $\mathrm{ECI}$ is the embedded $\mathrm{CO}_{2}$ index of UHPC, and $f_{c}$ is the compressive strength of UHPC in MPa.

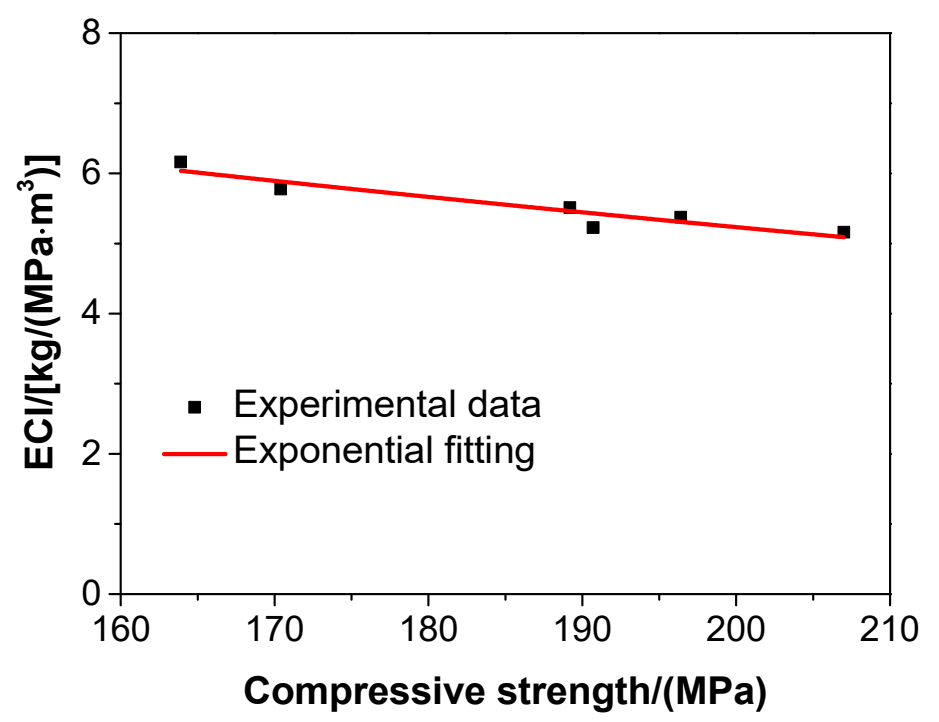

Figure 10. The relationship between the compressive and embedded $\mathrm{CO}_{2}$ index of the UHPC.

The $R$-square of the above equation was 0.8610 , which suggested that the exponential fitting was reliable. The compressive strength-ECI correlation of the UHPC displayed a significant negative correlation, which suggested that the environmental impact of UHPC was improved by increasing its compressive strength. In other words, it was feasible to produce UHPC with a lower environmental impact via improving its compressive strength.

In summary, the UHPC mix proportions used in this study were adequately designed according to the particle packing theory, and the experimental investigation provided basic information for the feasibility of aeolian sand in the production of UHPC. The findings indicated that aeolian sand could be successfully applied to develop a UHPC with better mechanical properties than those of the corresponding typical UHPC. That is, it is possible to use aeolian sand to manufacture UHPC. 
The environmental impact of UHPC could be improved by decreasing its water/binder ratio. As for the mechanism of high mechanical strength of UHPC with aeolian sand, further research is needed.

\section{Conclusions}

This work examined the feasibility of manufacturing UHPC with aeolian sand. The mix proportions of UHPC were designed according to the modified Andreasen \& Andersen particle packing theory. Both the ECI and UCI indexes were used to access the environmental impact of UHPC. The major conclusions of the present work are as follows:

(1) The mix proportions of UHPC with aeolian sand were adequately designed according to the particle packing theory, and it is possible to use aeolian sand to manufacture UHPC.

(2) The slump flow of UHPC decreased with a reduction in the water/binder ratio or an increase in the steel fibre content.

(3) The porosities of U0.18F3.0 and U0.16F3.0 were invariably lower than that of U0.20F3.0, which suggests that the porosity of UHPC decreases if the water/binder ratio is reduced.

(4) The compressive strength, flexural strength, and Young's modulus of UHPC samples with aeolian sand were in the ranges of 163.9-207.0 MPa, 18.0-32.2 MPa, and 49.3-58.9 GPa, respectively.

(5) The compressive strength, flexural strength, and Young's modulus of UHPC increased with a decrease in the water/binder ratio, except for U0.16F2.5. This indicates that the compressive strength, flexural strength, and Young's modulus of UHPC are improved when the water/binder ratio is reduced.

(6) The compressive strength, flexural strength, fracture energy, and Young's modulus of UHPC raised when the steel fibre content increased from 2.5 to $3.0 \mathrm{vol} \%$. This demonstrated that the adoption of steel fibre contributes to enhancing the compressive strength, flexural strength, plasticity, and Young's modulus of UHPC.

(7) The compressive strength-Young's modulus correlation of UHPC can be described by an exponential formula. This is a convenient practical method of assessing the Young's modulus of UHPC in terms of its compressive strength via the empirical formula.

(8) The environmental impact of UHPC was improved by decreasing the water/binder ratio, and the compressive strength-ECI correlation of UHPC displayed a significant negative correlation.

(9) The recommended value of steel fibre was $3.0 \mathrm{vol} \%$, considering the mechanical properties and the environmental impact of UHPC produced in the paper.

Author Contributions: Conceptualization, H.C.; Data curation, L.W. and F.W.; Funding acquisition, H.C.; Investigation, L.W. and T.F.; Methodology, H.C. and F.W.; Resources, F.W.; Visualization, T.F. and D.W.; Writing-original draft, H.C.; Writing-review and editing, F.W. and D.W. All authors have read and agreed to the published version of the manuscript.

Funding: The authors gratefully acknowledge the National Natural Science Foundation of China, China (51808294), the Natural Science Foundation of the Education Department of Jiangsu Province, China (general program, 18KJB430017), and the National Key Research and Development Program of China, China (2018YFC0705400).

Conflicts of Interest: The authors declare no conflict of interest.

\section{References}

1. Khan, I.H. Soil studies for highway construction in arid zones. Eng. Geol. 1982, 19, 47-62. [CrossRef]

2. Al-Sanad, H.; Ismael, N.; Nayfeh, A. Geotechnical properties of dune sands in Kuwait. Eng. Geol. 1993, 34, 45-52. [CrossRef]

3. Yuan, Y.; Wang, X.; Zhou, X. Experimental research on compaction characteristics of aeolian sand. Front. Arch. Civ. Eng. China 2008, 2, 359-365. [CrossRef]

4. Al-Taie, A.J.; Al-Shakarchi, Y.J.; Mohammed, A.A. Investigation of geotechnical specifications of sand dune soil: A case study around baiji in iraq. IIUM Eng. J. 2013, 14, 208-215. [CrossRef] 
5. Zhang, G.; Song, J.; Yang, J.; Liu, X. Performance of mortar and concrete made with a fine aggregate of desert sand. Build. Environ. 2006, 41, 1478-1481. [CrossRef]

6. Al-Harthy, A.S.; Halim, M.A.; Taha, R.; Al-Jabri, K. The properties of concrete made with fine dune sand. Constr. Build. Mater. 2007, 21, 1803-1808. [CrossRef]

7. Dong, W.; Shen, X.-D.; Xue, H.-J.; He, J.; Liu, Y. Research on the freeze-thaw cyclic test and damage model of Aeolian sand lightweight aggregate concrete. Constr. Build. Mater. 2016, 123, 792-799. [CrossRef]

8. Lopez-Querol, S.; Arias-Trujillo, J.; Gm-Elipe, M.; Matias-Sanchez, A.; Cantero, B. Improvement of the bearing capacity of confined and unconfined cement-stabilized aeolian sand. Constr. Build. Mater. 2017, 153, 374-384. [CrossRef]

9. Farzampour, A. Compressive behavior of concrete under environmental effects. In Compressive Strength of Concrete; IntechOpen: London, UK, 2019.

10. Farzampour, A. Temperature and humidity effects on behavior of grouts. Adv. Concr. Constr. 2017, 5, 659-669.

11. Mansouri, I.; Shahheidari, F.S.; Hashemi, S.M.A.; Farzampour, A. Investigation of steel fiber effects on concrete abrasion resistance. Adv. Concr. Constr. 2020, 9, 367-374.

12. Jiang, J.-Y.; Zhou, W.; Gao, Y.; Wang, L.; Wang, F.; Chu, H.-Y.; Xu, G.; Vandevyvere, B.; Sierens, Z.; Li, J. Feasibility of manufacturing ultra-high performance cement-based composites (UHPCCs) with recycled sand: A preliminary study. Waste Manag. 2018, 83, 104-112. [CrossRef] [PubMed]

13. Damineli, B.L.; Kemeid, F.M.; Aguiar, P.S.; John, V.M. Measuring the eco-efficiency of cement use. Cem. Concr. Compos. 2010, 32, 555-562. [CrossRef]

14. Rossi, P. Influence of fibre geometry and matrix maturity on the mechanical performance of ultra high-performance cement-based composites. Cem. Concr. Compos. 2013, 37, 246-248. [CrossRef]

15. El-Dieb, A.S. Mechanical, durability and microstructural characteristics of ultra-high-strength self-compacting concrete incorporating steel fibers. Mater. Des. 2009, 30, 4286-4292. [CrossRef]

16. Habert, G.; Denarié, E.; Šajna, A.; Rossi, P. Lowering the global warming impact of bridge rehabilitations by using Ultra High Performance Fibre Reinforced Concretes. Cem. Concr. Compos. 2013, 38, 1-11. [CrossRef]

17. Bornemann, R.; Schmidt, M. The role of powders in concrete. In Proceedings of the 6th International Symposium on Utilisation of High Strength/High Performance Concrete, Leipzig, Germany, 2 June 2002; pp. 863-872.

18. Huang, W.; Kazemi-Kamyab, H.; Sun, W.; Scrivener, K. Effect of replacement of silica fume with calcined clay on the hydration and microstructural development of eco-UHPFRC. Mater. Des. 2017, 121, 36-46. [CrossRef]

19. Brouwers, H.; Radix, H. Self-Compacting Concrete: Theoretical and experimental study. Cem. Concr. Res. 2005, 35, 2116-2136. [CrossRef]

20. Li, J.; Wu, C.; Hao, H. An experimental and numerical study of reinforced ultra-high performance concrete slabs under blast loads. Mater. Des. 2015, 82, 64-76. [CrossRef]

21. Hassan, A.; Jones, S.; Mahmud, G. Experimental test methods to determine the uniaxial tensile and compressive behaviour of ultra high performance fibre reinforced concrete (UHPFRC). Constr. Build. Mater. 2012, 37, 874-882. [CrossRef]

22. Alsalman, A.; Dang, C.; Hale, W.M. Development of ultra-high performance concrete with locally available materials. Constr. Build. Mater. 2017, 133, 135-145. [CrossRef]

23. Verma, M.; Prem, P.R.; Rajasankar, J.; Bharatkumar, B. On low-energy impact response of ultra-high performance concrete (UHPC) panels. Mater. Des. 2016, 92, 853-865. [CrossRef]

24. Tafraoui, A.; Escadeillas, G.; Vidal, T. Durability of the Ultra High Performances Concrete containing metakaolin. Constr. Build. Mater. 2016, 112, 980-987. [CrossRef]

25. Shafieifar, M.; Farzad, M.; Azizinamini, A. Experimental and numerical study on mechanical properties of Ultra High Performance Concrete (UHPC). Constr. Build. Mater. 2017, 156, 402-411. [CrossRef]

26. Hüsken, G.; Brouwers, H.J.H. Erratum to: A new mix design concept for earth-moist concrete: A theoretical and experimental study. Cem. Concr. Res. 2008, 38, 1246-1259. [CrossRef]

27. Yu, R.; Spiesz, P.; Brouwers, H. Effect of nano-silica on the hydration and microstructure development of Ultra-High Performance Concrete (UHPC) with a low binder amount. Constr. Build. Mater. 2014, 65, 140-150. [CrossRef]

28. Yu, R.; Spiesz, P.; Brouwers, H. Mix design and properties assessment of Ultra-High Performance Fibre Reinforced Concrete (UHPFRC). Cem. Concr. Res. 2014, 56, 29-39. [CrossRef] 
29. Pyo, S.; Kim, H.-K.; Lee, B.Y. Effects of coarser fine aggregate on tensile properties of ultra high performance concrete. Cem. Concr. Compos. 2017, 84, 28-35. [CrossRef]

30. Wang, X.; Yu, R.; Shui, Z.; Song, Q.; Zhang, Z. Mix design and characteristics evaluation of an eco-friendly Ultra-High Performance Concrete incorporating recycled coral based materials. J. Clean. Prod. 2017, 165, 70-80. [CrossRef]

31. Funk, J.E.; Dinger, D.R. Predictive Process Control of Crowded Particulate Suspensions Applied to Ceramic Manufacturing; Kluwer Academic Publishers: Boston, MA, USA, 1994.

32. Kim, H.; Koh, T.; Pyo, S. Enhancing flowability and sustainability of ultra high performance concrete incorporating high replacement levels of industrial slags. Constr. Build. Mater. 2016, 123, 153-160. [CrossRef]

33. Wille, K.; Boisvert-Cotulio, C. Material efficiency in the design of ultra-high performance concrete. Constr. Build. Mater. 2015, 86, 33-43. [CrossRef]

34. Park, S.H.; Kim, D.-J.; Ryu, G.-S.; Koh, K.T. Tensile behavior of Ultra High Performance Hybrid Fiber Reinforced Concrete. Cem. Concr. Compos. 2012, 34, 172-184. [CrossRef]

35. GB 50204. In Code for Quality Acceptance of Concrete Structure Construction; China Architecture \& Building Press: Beijing, China, 2014.

36. GB 50119. In Code for Concrete Admixture Application; China Architecture \& Building Press: Beijing, China, 2014.

37. GB/T 17671. In Method of Testing Cements-Determination of Strength; Standards Press of China: Beijing, China, 1999.

38. Long, G.; Gao, Y.; Xie, Y. Designing more sustainable and greener self-compacting concrete. Constr. Build. Mater. 2015, 84, 301-306. [CrossRef]

39. Chiaia, B.; Fantilli, A.P.; Guerini, A. Eco-mechanical index for structural concrete. Constr. Build. Mater. 2014, 67, 386-392. [CrossRef]

40. Wang, R.; Gao, X.; Huang, H.; Han, G. Influence of rheological properties of cement mortar on steel fiber distribution in UHPC. Constr. Build. Mater. 2017, 144, 65-73. [CrossRef]

41. Alsalman, A.; Dang, C.N.; Prinz, G.S.; Hale, W.M. Evaluation of modulus of elasticity of ultra-high performance concrete. Constr. Build. Mater. 2017, 153, 918-928. [CrossRef]

42. Wu, Z.; Shi, C.; He, W.; Wu, L. Effects of steel fiber content and shape on mechanical properties of ultra high performance concrete. Constr. Build. Mater. 2016, 103, 8-14. [CrossRef]

43. Chu, H.-Y.; Jiang, J.-Y.; Sun, W.; Zhang, M. Effects of graphene sulfonate nanosheets on mechanical and thermal properties of sacrificial concrete during high temperature exposure. Cem. Concr. Compos. 2017, 82, 252-264. [CrossRef]

44. Meng, W.; Khayat, K.H. Mechanical properties of ultra-high-performance concrete enhanced with graphite nanoplatelets and carbon nanofibers. Compos. Part B Eng. 2016, 107, 113-122. [CrossRef]

45. Chu, H.-Y.; Ge, X.; Jiang, J.-Y.; Tang, J.; Zhang, Z. Mechanical properties and ablation behaviour of nuclear sacrificial materials containing graphene sulfonate nanosheets. Constr. Build. Mater. 2018, 191, 69-79. [CrossRef]

46. Wang, L.-G.; Ju, S.-Y.; Chu, H.-Y.; Liu, Z.-Y.; Yang, Z.-Q.; Wang, F.-J.; Jiang, J. Hydration process and microstructure evolution of low exothermic concrete produced with urea. Constr. Build. Mater. 2020, 248, 118640. [CrossRef]

47. Jiang, J.-Y.; Zhou, W.; Chu, H.; Wang, F.; Wang, L.; Feng, T.; Guo, D. Design of Eco-friendly Ultra-high Performance Concrete with Supplementary Cementitious Materials and Coarse Aggregate. J. Wuhan Univ. Technol. Sci. Ed. 2019, 34, 1350-1359. [CrossRef]

48. Chu, H.-Y.; Jiang, J.-Y.; Sun, W.; Zhang, M. Thermal behavior of siliceous and ferro-siliceous sacrificial concrete subjected to elevated temperatures. Mater. Des. 2016, 95, 470-480. [CrossRef]

49. Yu, R.; Spiesz, P.; Brouwers, H. Development of an eco-friendly Ultra-High Performance Concrete (UHPC) with efficient cement and mineral admixtures uses. Cem. Concr. Compos. 2015, 55, 383-394. [CrossRef]

50. Yoo, D.-Y.; Banthia, N.; Lee, J.-Y.; Yoon, Y.-S. Effect of fiber geometric property on rate dependent flexural behavior of ultra-high-performance cementitious composite. Cem. Concr. Compos. 2018, 86, 57-71. [CrossRef]

51. Siddique, R. Effect of fine aggregate replacement with Class F fly ash on the mechanical properties of concrete. Cem. Concr. Res. 2003, 33, 539-547. [CrossRef]

52. Su, Y.; Wu, C.; Li, J.; Li, Z.-X.; Li, W. Development of novel ultra-high performance concrete: From material to structure. Constr. Build. Mater. 2017, 135, 517-528. [CrossRef] 
53. Bazant, Z.P. Fracture mechanics of concrete structures. In Proceedings of the First International Conference on Fracture Mechanics of Concrete Structures (FraMCoS1), held at Beaver Run Resort, Breckenridge, CO, USA, 1-5 June 1992; Taylor \& Francis: London, UK.

54. Harsh, S.; Shen, Z.; Darwin, D. Strain-rate sensitive behavior of cement paste and mortar in compression. ACI Mater. J. 1990, 87, 508-516.

55. Shi, Y.; Long, G.; Ma, C.; Xie, Y.; He, J. Design and preparation of ultra-high performance concrete with low environmental impact. J. Clean. Prod. 2019, 214, 633-643. [CrossRef]

(C) 2020 by the authors. Licensee MDPI, Basel, Switzerland. This article is an open access article distributed under the terms and conditions of the Creative Commons Attribution (CC BY) license (http://creativecommons.org/licenses/by/4.0/). 